quite different notation is employed-is simply infuriating ! I would urge upon Prof. Pearson that he has now an unrivalled opportunity of fixing in the language of English (and perhaps foreign) mathematicians a really serviceable and significant system of notation.

The double-suffix notation for strain and stress, which is developed to perfection in St. Venant's French translation of Clebsch, has many advantages, but seems to be too cumbrous for English taste. Nothing perhaps could be more unmeaning than Thomson and Tait's notation for "stresses," independent as it is of all reference to the strain-symbols. Still I must confess (in common, I dare say, with most men who have derived their first inspirations from that mathematical epic) that it has secured too firm a place in my mental machinery to be lightly cast out, even in favour of a better.

Cambridge, May I2

\section{The Colours of Arctic and Alpine Animals}

Mr. R. Meldola has maintained, in Nature, vol. xxxi. p. 505, the idea that the white colour of some animals, Arctic mammals and birds, must be ascribed to the absorbent and radiating power of the same colorations in relation to the rays of the sun. He maintains also that to a similar cause we owe the seasonal polychromism of several mammals and birds of the Alps, and what would be for these animals a partial return to the characters of the Glacial epoch.

By an analogous theory the author explains the contrary phenomenon that is observed in many insects-that is, the darkening of the coloration, and he speaks principally on this point of the Lepidoptera.

Now I beg to make the following observations, and to indicate the following facts:-

(I) That a seasonal mutation of colour is observable in many mammals, now more, now less distinctly, and generally it concurs with the change of coat. Also not seldom in mammals strictly belonging to the Alps, as, for example, in the Rupicapra europea, and in the Capra ibex, the colour changes very little in the summer and in the winter, although the length, the thickness, and also the coarseness of the hairs were very different. In other cases, as, for example, in the Cervus mandarimus, ${ }^{1}$ the coat is, in summer, light reddish yellow, with many round white spots, while in winter it is dark brown, and the round spots are less numerous and are light brown.

(2) As to the insects, it is observed that in Coleoptera the colours of the Alpine species are brighter than those of the warmer plains, as in the genera of Carabus, Pterostichus, \&c. Inż several species of Harpalus, Amara, Cicindelis, \&c., the individuals that we find at the greatest elevations of the Alps have often lighter colours.

(3) A darker colour and sometimes a whole melanism is observed in general in the insects of the deserts-for example, in that of Sahara. On the contrary, the mammals of these countries present in general a very light colour. It seems to me that this fact cannot be explained by the theory of radiation.

(4) A very remarkable melanism is also observed in several mammals, the Reptilia and Coleoptera that are in little islands, or upon rocks in the warmest regions, for example the L. muralis, \&c., Cicindela campestris, in the island of St. Peter in Sardinia. ${ }^{2}$

(5) In the reptiles and in the Alpine amphibia we sometimes meet with some cases of darkening, but the cases of a remarkable brightening are not very rare, as, for example, in the tadpoles of Rana muta.

(6) A sensible difference is observed in the coloration between the Arctic birds and the Antarctic. In these last black is much more abundant.

Indeed, Australia, New Zealand, \&c., are countries known for a remarkable darkening in the colours of many sorts of animals.

In the Carnivora, which are the mammals that chiefly present seasonal polychromism and white colour, is observed a tendency to this colour in several forms that, however, do not live either in Polar regions or in very cold places. As to this fact the colour of the genera Zorilla, Meles, \&c., and also the very curious Ailurus melanoleucus of Thibet, ${ }^{3}$ should be observed.

I Milne-Edwards, "Recherches pour servir à l'Histoire Naturelle des Mammifères," tav. 22, 2za. Paris: Masson.

${ }_{2}$ Si consulti L. Camerano, "Richercheinterno alla Distribuzione dei Colcri nel Regno animale." Ment. R. Accal. Scienze di Torino.

3 Milne-Edwards.
The causes, I would say in conclusion, that intervene to modify the colour of animals, are very complicated; climate has amongst these a certain importance, but it does not seem to me that, although it be very attractive, Mr. Meldola's theory of radiation is sufficient.

Zoological Museum of Turin

\section{On Certain Stages of Ocular After-Images}

IN a short note in the Phil. Mag., 1872, vol, xliii. p. 343, Prof. C. A. Young has recorded a curious instance of "afterimage," which seems to me to be of the same order as that observed by Mr. Shelford Bidwell, and recorded in NATURE, (vol. xxxii. p. 30). I quote from Prof. Young's note, which is named "Note on Recurrent Vision," a few lines, which will show what his observation was :-

"In the course of some experiments with a new double-plate Holtz machine belonging to the College (Dartmouth, America), I have come upon a very curious phenomenon, which I do not remember ever to have seen noticed. The machine gives easily intense Leyden-jar sparks from 7 to 9 inches in length, and of most dazzling brilliance, at the rate of seventy a minute. When, in a darkened room, the eye is screened from the direct light of the spark, the illumination produced is sufficient to render everything in the apartment perfectly visible; and, what is remarkable, every conspicuous object is seen twice at least, with an interval of a trifle less than a quarter of a second-the first time vividly, the second time faintly; often it is seen a third, and sometimes (but only with great difficulty) even a fourth time."

Prof. Young shows that it is a subjective phenomenon, and measures the interval between the first and second seeing of an object, giving as the mean of twelve experiments the interval 0.22 second for the case of his own eyes, and 0.24 second for that of another observer.

Five or six years ago I observed another instance of what I believe to be the same kind of "after-image," though at first I was inclined, being engaged upon experiments with a view to finding the cause of certain ocular "ghosts" due to multiple reflection inside the eye (Proc. Roy. Soc., No. 223, 1883), to ascribe it to a different cause. It was seen in a room lighted only by the bright glow of coals in the grate. Whenever the eyes were suddenly flashed across the fireplace, and then fixed on some object $50^{\circ}$ or $60^{\circ}$ from it, there appeared a faint blue light, which seemed to flash from the object to the glow. This phenomenon was much more strongly marked at some times than others, and varied with some cause which I never further investigated. Later I came upon another instance of the same thing; and as this is the easiest to reproduce, and one by which one may best study the phenomena, I will describe it.

Let a match or a splinter of wood be made to glow, as for testing oxygen, and let it be observed in a dark room; the eyes should be fixed, and the glowing match moved about. I found that for purposes of rough measurement a most convenient curve of motion is a figure of 8 on its side in a vertical plane $(\infty)$. Also it is convenient to keep the period of the movernent the same, and to vary the size of the curve if change of velocity is required. There are difficulties to be overcome in regulating the brilliancy of the light (Mr. Bidwell has pointed out the necessity of a certain degree of brilliancy in the case of the vacuum tubes), if a systematic investigation were undertaken; a glowing match becomes brighter the quicker the movement; the reverse is the case with a platinum wire carrying a strong current of electricity; and a small incandescent lamp is objectionable on account of reflection from its glass case.

I shall consider the "after-images" of the glowing-point as forming a trail, in which all the changes are set out at the same monent, and proceed to describe the trail for two cases. I should state that following descriptions refer to the trails as seen by me in the evening; for there are very considerable variations in the phenomena according as the eye is likely to be wearied or fresh. I may also repeat Mr. Bidwell's caution that it is by no means.certain that a person new to the subject will at first be able to see the appearances described.

I arrange a metronome beating seconds, and move the glow. ing-point so as to describe the curve completely in two seconds. First, let the figure of eight be only as large as can be got into a rectangle 3 inches by $\mathrm{I} \frac{1}{2}$. In this case there comes after the glowing-point a dark interval in the trail, about an inch long; then a distinct blue-green ghost, about the same size as the 